\title{
Phase 3 study comparing weekly concomitant boost for breast cancer patients treated with conservative breast surgery with sequential boost.
}

\author{
Mohamad Soliman, Ali Mohammed ,Emad Eldin Nabil, Asmaa Hussein
}

Background: Radiation therapy after breast conserving surgery is a standard part of treatment for invasive breast cancer. Based on radiobiological models, it was found that shorter hypofractiontaed radiation schedules had equivalent local control to standard radiation therapy. Radiation boost to the tumor bed was evident to be associated with significant improvement in local control.

Methods: This study included 48 female patients with early breast cancer who underwent breast conservative surgery. There were two arm of radiation, hypofractionated radiotherapy with concomitant boost (group A) - hypofractionated radiotherapy with sequential boost (group B).

Results: after median follow up 43 months range (21-57). Four year over all survival rate for concomitant boost arm was (91.67\%) and sequential boost arm was (87.50\%), Four year disease free survival rate for concomitant boost arm was $(87.5 \%)$ and sequential boost arm was $(79.17 \%)$. late skin toxicity, grade 0 was $(72.73 \%)$ in concomitant boost arm and (54.55\%) in sequential boost arm and grade 1 was (9.09\%) in concomitant boost arm and (31.82\%) in sequential boost arm and grade 2 was (18.19) in concomitant boost arm and (13.55\%) in sequential boost arm, grade 3 late lung toxicity was (4.17\%) in concomitant boost arm and $(12.50 \%)$ in sequential boost arm, cardiac toxicity in concomitant boost arm (8.33\%) and sequential boost arm (16.67\%).The ipsilateral lymphedema after 24 months of follow up G2 (4.55\%) in concomitant boost arm G3 (4.55\%) in in sequential boost arm.

Conclusion: A shortened whole breast irradiation schedule with a weekly concomitant boost may be an alternative option with acceptable toxicity and excellent cosmesis.

\section{Introduction}

Breast-conserving therapy (BCT) for early stage result in survival rate equivalent to that of mastectomy, therefore BCT became the standard treatment of stage I- II breast cancer [1]. Radiation therapy represents the standard adjuvant treatment after breast conserving surgery (BCS) as it associated with a $70 \%$ reduction in the risk of recurrence [2] and a 9-12\% reduction in the risk of death [3]. Conventional radiotherapy given in 6-7 weeks has economic and logistic load on radiotherapy departments as well as negative impact on patient's quality of life. Recent randomized trials have confirmed that hypofractioned wholebreast irradiation is equivalent to more conventional whole-breast irradiation with respect to local recurrence and cosmetic outcome [4]. In order to intensify treatment, a simultaneous boost dose, concomitant or integrated, has been introduced in clinics by using 3-D conformal radiotherapy [5]. Current study being prospective in nature to confirm the feasibility of weekly concomitant boost and comparability in term of local control, toxicity, survival to sequential boost.

\section{Patients and Methods}

This prospective study included 48 female patients with early breast cancer. Who received adjuvant radiotherapy in the radiotherapy department in Sohage University Hospital, Egypt, in period between March, 2014 and July, 2018 Patients 
with age of 18 years and above, with all histological types and grades, pathological T1-T2 tumors, N0 and N1 disease with negative surgical margins after breast conservative surgery. Were eligible and written consent was taken from each patient then randomly Allocated into two groups.

A- The total whole breast radiation dose was 42.5 Gy in 16 fractions while the area of the lumpectomy cavity received additional 3Gy through once weekly 1 Gy concomitant boost.

B- The total whole breast radiation dose was 42.5 Gy in 16 fractions followed by sequential boost.

\section{Radiation:}

Patients treated in the supine position on a wedged board with both arm abducted and externally rotated. CT planning in CT simulation will patient in the same treatment position was used for the localization and determination of the target volumes, organ at risk, and the field arrangement. The CT scans were done in the supine position from the level of the larynx to the upper abdomen with both lungs were included and the scan thickness was $5 \mathrm{~mm}$. The Whole Breast Clinical Target Volume (WBCTV) included the glandular breast tissue. The Whole Breast Planning
Target Volume (WB-PTV) was generated by the addition of a $5 \mathrm{~mm}$ margin around the WB-CTV. The Boost Clinical Target Volume (CBCTV) was generated by adding at least a $10 \mathrm{~mm}$ margin around the lumpectomy cavity and the corresponding PTV (CB-PTV) created by adding a further $5 \mathrm{~mm}$ margin. The total whole breast radiation dose was 42.5 Gy in 16 fractions while the area of the lumpectomy cavity received additional 3Gy through once weekly 1 Gy concomitant photon boost in group A or received additional 10-16 Gy a sequential boost in group B.

\section{Assessment and Follow up:}

Clinical evaluations were performed weekly during treatment course for assessment of acute toxicity. A followup evaluation was performed every three months after treatment end for evaluation of the late radiation toxicity, disease free survival and local control. all patient evaluated by ECHO before radiotherapy and every 6 month after treatment to monitor change in left ventricular ejection fraction in comparison with base line assment. The RTOG scoring system for radiation reactions was used to score radiation toxicity. 
SOHAG MEDICAL JOURNAL Phase 3 study comparing weekly concomitant boost Vol. 23 No.1 Jan 2019 Asmaa Hussein.et al

\section{Results}

\begin{tabular}{|c|c|c|c|}
\hline Variable & $\begin{array}{c}\text { Concomitant boost } \\
\mathrm{N}=24\end{array}$ & $\begin{array}{c}\text { Sequential boost } \\
N=24\end{array}$ & $P$ value \\
\hline $\begin{array}{l}\text { Age/years } \\
\text { Mean } \pm \text { SD } \\
\text { Median (range) }\end{array}$ & $\begin{array}{r}45.92 \pm 7.37 \\
46(27-60)\end{array}$ & $\begin{array}{c}50.17 \pm 10.82 \\
51(33-65)\end{array}$ & 0.12 \\
\hline $\begin{array}{l}\text { Site } \\
\text { Right } \\
\text { Left }\end{array}$ & $\begin{array}{l}13(54.17 \%) \\
11(45.83 \%)\end{array}$ & $\begin{array}{c}7(29.17 \%) \\
17(70.83 \%)\end{array}$ & 0.08 \\
\hline $\begin{array}{l}\text { Quadrant } \\
\text { Lower inner } \\
\text { Lower outer } \\
\text { Supra areolar } \\
\text { Upper inner } \\
\text { Upper outer }\end{array}$ & $\begin{array}{l}4(16.67 \%) \\
2(8.33 \%) \\
3(12.50 \%) \\
1(4.17 \%) \\
14(58.33 \%)\end{array}$ & $\begin{array}{c}2(8.33 \%) \\
7(29.17 \%) \\
1(4.17 \%) \\
4(16.67 \%) \\
10(41.67 \%)\end{array}$ & 0.14 \\
\hline $\begin{array}{l}\text { Pathology } \\
\text { IDCA }\end{array}$ & $24(100 \%)$ & $24(100 \%)$ & 1.00 \\
\hline $\begin{array}{l}\text { Tumor grade } \\
2 \\
3 \\
\end{array}$ & $\begin{array}{l}22(91.67 \%) \\
2(8.33 \%) \\
\end{array}$ & $\begin{array}{c}23(95.83 \%) \\
1(4.17 \%) \\
\end{array}$ & 1.00 \\
\hline $\begin{array}{l}\text { Tumor size } \\
\text { Mean } \pm \text { SD } \\
\text { Median (range) } \\
\end{array}$ & $\begin{array}{l}2.70 \pm 0.77 \\
2.75(1.5-4)\end{array}$ & $\begin{array}{c}2.66 \pm 0.79 \\
2.5(1-4) \\
\end{array}$ & 0.85 \\
\hline $\begin{array}{l}\text { Number of positive } \mathbf{L N} \\
\text { Mean } \pm \text { SD } \\
\text { Median (range) }\end{array}$ & $\begin{array}{c}1 \pm 1.28 \\
0(0-3)\end{array}$ & $\begin{array}{c}1.25 \pm 1.26 \\
1(0-3)\end{array}$ & 0.47 \\
\hline $\begin{array}{l}\text { Number of removed LN } \\
\text { Mean } \pm \text { SD } \\
\text { Median (range) }\end{array}$ & $\begin{array}{l}22.08 \pm 6.20 \\
22(12-39)\end{array}$ & $\begin{array}{c}16.29 \pm 5.66 \\
14(6-25) \\
\end{array}$ & 0.003 \\
\hline $\begin{array}{l}\text { Estrogen receptors } \\
\text { Negative } \\
\text { Positive } \\
\end{array}$ & $\begin{array}{l}5(20.83 \%) \\
19(79.17 \%) \\
\end{array}$ & $\begin{array}{c}8(33.33 \%) \\
16(66.67 \%) \\
\end{array}$ & 0.33 \\
\hline $\begin{array}{l}\text { Progesterone receptors } \\
\text { Negative } \\
\text { Positive } \\
\end{array}$ & $\begin{array}{l}7(29.17 \%) \\
17(70.83 \%)\end{array}$ & $\begin{array}{l}8(33.33 \%) \\
16(66.67 \%)\end{array}$ & 0.76 \\
\hline $\begin{array}{l}\text { HER2 } \\
\text { Negative } \\
\text { Positive } \\
\end{array}$ & $\begin{array}{c}17(70.83 \%) \\
7(29.17 \%)\end{array}$ & $\begin{array}{c}17(70.83 \%) \\
7(29.17 \%)\end{array}$ & 1.00 \\
\hline
\end{tabular}

Table (1) Patients characteristic in concomitant and sequential boost groups 
SOHAG MEDICAL JOURNAL Vol. 23 No.1 Jan 2019
Phase 3 study comparing weekly concomitant boost Asmaa Hussein.et al

\begin{tabular}{|l|c|c|c|}
\hline Variable & $\begin{array}{c}\text { Concomitant boost } \\
\mathbf{N = 2 4}\end{array}$ & $\begin{array}{c}\text { Sequential boost } \\
\mathbf{N = 2 4}\end{array}$ & P value \\
\hline Acute skin toxicity & & & \\
G0 & $8(33.33 \%)$ & $4(16.67 \%)$ & \\
G1 dry desquamation & $10(41.67 \%)$ & $6(25.00 \%)$ & \multirow{2}{*}{0.18} \\
G1 mild erythema & $3(12.50 \%)$ & $3(12.50 \%)$ & \\
G2 tender erythema & $2(8.33 \%)$ & $4(16.67 \%)$ & \\
G3 moist desquamation & $1(4.17 \%)$ & $6(25.00 \%)$ & \\
G4 ulceration & 0 & $1(4.17 \%)$ & \\
\hline Late skin toxicity 12ms & $8(33.33 \%)$ & $5(20.83 \%)$ & \\
G0 & $5(20.83 \%)$ & $3(12.50 \%)$ & \multirow{2}{*}{0.19} \\
G1 & $10(41.66 \%)$ & $16(66.67 \%)$ & \\
G2 & $1(4.17 \%)$ & 0 & \\
G3 & & $\mathrm{N}=22$ & \\
& $\mathrm{~N}=22$ & $14(54.55 \%)$ & \\
\hline Late skin toxicity 24ms & $16(72.73 \%)$ & $7(31.82 \%)$ & 0.24 \\
G0 & $2(9.09 \%)$ & $3(13.64 \%)$ & \\
G1 & $4(18.19 \%)$ & & \\
G2 & &
\end{tabular}

Table (2) skin toxicity in concomitant and sequential radiotherapy boost groups

\begin{tabular}{|l|c|c|c|}
\hline Variable & $\begin{array}{c}\text { Concomitant boost } \\
\mathrm{N}=24\end{array}$ & $\begin{array}{c}\text { Sequential boost } \\
\mathrm{N}=24\end{array}$ & P value \\
\hline Acute lung toxicity & $\begin{array}{c}23(95.83 \%) \\
\text { G0 }\end{array}$ & $\begin{array}{c}23(95.83 \%) \\
1(4.17 \%)\end{array}$ & 1.00 \\
G2 cough dyspnea & $1(4.17 \%)$ & $21(87.50 \%)$ & 0.30 \\
\hline Late lung toxicity & $23(95.83 \%)$ & $3(12.50 \%)$ & \\
G0 & $1(4.17 \%)$ & $20(83.33 \%)$ & 0.38 \\
G3 dense radiograph & $22(91.67 \%)$ & $4(16.67 \%)$ & \\
\hline Heart toxicity & $2(8.33 \%)$ & \\
No & &
\end{tabular}

Table (3) lung and heart toxicity in concomitant and sequential radiotherapy boost groups

\begin{tabular}{|l|c|c|c|}
\hline Variable & $\begin{array}{c}\text { Concomitant boost } \\
\mathrm{N}=24\end{array}$ & $\begin{array}{c}\text { Sequential boost } \\
\mathrm{N}=24\end{array}$ & P value \\
\hline Arm lymphedema before RT & $22(91.67 \%)$ & $24(100 \%)$ & \\
G0 & $2(8.33 \%)$ & 0 & 0.15 \\
G1 mild lymphedema & $19(79.17 \%)$ & $22(91.67 \%)$ & \\
\hline Arm lymphedema after12 ms of & $2(8.33 \%)$ & $1(4.17 \%)$ & 0.24 \\
RT & $3(12.50 \%)$ & $1(4.17 \%)$ & \\
G0 & $\mathrm{N}=22$ & $\mathrm{~N}=22$ & \\
G1 mild lymphedema & $21(95.45 \%)$ & $21(95.45 \%)$ & 0.37 \\
G2 moderate lymphedema & $1(4.55 \%)$ & 0 & 0.37 \\
\hline Arm lymphedema after24 ms of & 0 & $1(4.55 \%)$ & \\
RT & & & \\
G0 & & \\
G2 moderate lymphedema & & \\
G3 severe lymphedema &
\end{tabular}

Table (4) Arm lymphedema in concomitant and sequential radiotherapy boost groups 
SOHAG MEDICAL JOURNAL

Vol. 23 No.1 Jan 2019
Phase 3 study comparing weekly concomitant boost Asmaa Hussein.et al

\begin{tabular}{|l|c|l|l|}
\hline Variable & $\begin{array}{c}\text { Concomitant boost } \\
\mathbf{N = 2 4}\end{array}$ & $\begin{array}{c}\text { Sequential boost } \\
\mathbf{N = 2 4}\end{array}$ & P value \\
\hline $\begin{array}{l}\text { Time from diagnosis } \\
\text { to death/end of study } \\
\text { Mean } \pm \text { SD }\end{array}$ & & & \\
Median (range) & $3.65 \pm 0.82$ & $3.45 \pm 0.82$ & 0.42 \\
\hline Death & $3.70(2.04-4.86)$ & $3.50(1.76-4.69)$ & \\
No & $22(91.67 \%)$ & $21(87.50 \%)$ & 1.00 \\
Yes & $2(8.33 \%)$ & $3(12.50 \%)$ & \\
\hline Time from surgery to & & & \\
recurrence/end of & & $3.19 \pm 1.08$ & 0.36 \\
study & $3.47 \pm 1.03$ & $3.42(1.05-4.69)$ & \\
Mean \pm SD & $3.68(1.20-4.80)$ & & 0.44 \\
Median (range) & & $5(20.83 \%)$ & 1.00 \\
Recurrence & $3(12.50 \%)$ & 0 & 1.00 \\
All & 0 & $4(16.67 \%)$ & 1.00 \\
Local & $3(12.50 \%)$ & $1(4.17 \%)$ & \\
Distance & 0 & & \\
Nodal & &
\end{tabular}

Table (5) Follow up and fate in concomitant and sequential radiotherapy boost groups

\section{Discussion}

In our study follow up schedule from time of diagnosis till end of study or death, time of surgery till end of study or recurrence showed no statistically significant difference Table (5) with median follow up 43 months range (21-57). Four year OS rate for group A was $(91.67 \%)$ and group B was $(87.50 \%)$ with no statistically significant difference $\mathrm{P}$ value $=1.00$, Four year disease free survival rate for group A was (87.5\%) and group B was $(79.17 \%)$ with no statistically significant difference $P$ value $=0.44$ while Corvo et al [7] median follow-up 33 months, range: $24-41$ months, Two year disease free survival rate $(94.6 \%)$. Regarding the treatment outcomes incidence of death for group A was $(8.33 \%)$ and for group B was $(12.50 \%)$ with no statistically significant difference $P$ value $=1.00$.

disease relapse occurred only in 8 patients $(33.34 \%)$, Distance recurrence for group A was 3 (12.50\%) and group
B was 4 (16.67\%), one patient in group B $(4.17 \%)$ developed nodal recurrence, with no statistically significant difference $\mathrm{P}$ value $=0$, 44, while Corvo et al [7] disease relapse was $5.4 \%$.

Acute skin complication in our study were assessed during the treatment and up to 12 weeks, The incidence of grade 1 (dry desquamation) was (41.67\%) in group A and $(25.00 \%)$ in group B and grade 2 was $(8.33 \%)$ in group $A$ and $(16.67 \%)$ in group B. but acute skin toxicity reported at Guenze et al [6] where grade $1(39 \%)$ grade 2 was $9 \%$. While Corvo et al [7] reported $12 \%$ of patients developed grade 2 acute skin toxicity so our results are comparable to that shown in the reported studies.

In our study late skin toxicity $24 \mathrm{~ms}$, the incidence of grade 0 was $(72.73 \%)$ in group A and $(54.55 \%)$ in group B and grade 1 was $(9.09 \%)$ in group A and $(31.82 \%)$ in group $\mathrm{B}$ and grade 2 was (18.19) in group A and (13.55\%) in group $\mathrm{B}$, but late skin toxicity 
reported at Guenze et al [6]. where G0 $(52 \%)$ G1 (45\%) G2 (3\%) while late skin toxicity reported at Corvo et al[7] where G0 in $92 \%, \mathrm{G} 1$ in $7 \%$ and $\mathrm{G} 2$ in $1 \%$ of patients, so our results are comparable to that shown in the reported studies as regard incidence of grade 1 late skin toxicity in group A .

In our study, the acute radiation induced pnumonitis was reported as grade 2 was $(4.17 \%)$ in both groups, while the chronic toxicity reported as grade 3 late lung toxicity was $(4.17 \%)$ in group A and (12.50\%) in group B. These results also are comparable to those reported by Shahid et al [8], where $5 \%$ of patients developed acute pulmonary radiation toxicity and ElHadaad et al [9] grade 1 late lung toxicity was $5.5 \%$.

In our study, the cardiac toxicity was evaluated by measuring the left ventricular ejection fraction at base line and every 6 months after radiotherapy. In our study we had only two patients in group A $(8.33 \%)$ and four patients in group B (16.67\%) who showed drop more than $10 \%$ below the base line left ventricular ejection fraction (LVEF). while Shahid et al[8] reported that cardiac toxicity occurred in $5 \%$ to $6 \%$ of patients between the three hypo fractionated schedules so our patients showed more toxicity as most of patients received anthracyclin combined with taxan based chemotherapy and tamoxifen as hormonal treatment and some patients received trastuzomab contaning regmin Regarding the ipsilateral lymphedema, in our study 12 at months of follow up G1 lymphedema $(8.33 \%)$ in group A, $(4.17 \%)$ in group B, G2 moderate lymphedema $(12.50 \%)$ in group $\mathrm{A}$ $(4.17 \%)$ in groupB. After 24 months of follow up G2 moderate lymphedema $(4.55 \%)$ in group A G3 severe lymphedema $(4.55 \%)$ in groupB while Shahid et al[8]reported that G2 and G3 lymphedoema was $21 \%, 22 \%$ and
$27 \%$ between the three hypo fractionated schedules. recently published systematic review and metaanalysis on the incidence of unilateral lymphedema after breast cancer where a pooled estimate of lymphedema in the 72 studies showed an incidence of edema of $16.6 \%$ as reported by Disipio et al [10].Our lower rates of lymphedema toxicity may be due to avoid using axillary radiation in separate fields in node positive patients.

\section{Conclusion}

We suggest that this radiation schedule may provide an alternative option to conventional WBI with acceptable acute and late toxicity, good compliance and excellent cosmesis.

\section{References}

1. Fisher B, Anderson S, Bryant J, et al: Twenty-year follow-up of a randomized trial comparing total mastectomy, lumpectomy, and lumpectomy plusirradiation for the treatment of invasive breast cancer. $\mathrm{N}$ Engl J Med. 2002; (347):1233-1241.

2. Cuzick J, Stewart H, Peto R, et al: Effect of radiotherapy after breastconserving surgery on 10-year recurrence and 15-year breast cancer death: meta-analysis of individual patient data for 10801 women in 17 randomised trials. Lancet 2011; 378(9804): 1707-1716.

3. Clarke M, Collins R, Darby S, et al: Effects of radiotherapy and of differences in the extent of surgery for early breast cancer on local recurrence and 15-year survival: an overview of the randomised trials. Lancet 2005; 366:2087-2106.

4. Whelan TJ, Pignol JP, Levine MN, et al: Long-term results of hypofractionated radiation therapy for breast cancer. N Engl J Med 2010; 362(6):513-520.

5. Van der Laan HP, Dolsma WV, Maduro JH, Korevaar EW, Hollander M,Langendijk JA: Three-dimensional conformal simultaneously 
integratedboost technique for breastconserving radiotherapy. Int $\mathrm{J}$ Radiat OncolBiol Phys 2007, 68(4):1018-23.

6. Guenzi M, Vagge S, AzinwN, et al: A biologically competitive 21 days hypofractionation scheme with weekly concomitant boost in breast cancer radiotherapy feasibility acute sub-acute and short term late effects Radiat Oncol. 2010; 5: 111

7. Corvo R, Ricchetti F, Doino D, et al: Adjuvant hypo fractionated radiotherapy with weekly concomitant boost for women with early breast cancer: the clinical experience at Genoa University. Anticancer Res2010; 30: 4749-4753
8. Shahid A, Athar MA, Asghar S, et al: Post mastectomy adjuvant radiotherapy in breast cancer: a comparision of three hypofractionated protocols. J Pak Med Assoc. 2009; 59(5):282-7.

9. El-Hadaad, H.A., Wahba, H.A., Elnahas, W. and Roshdy, S. (2016) Concomitant Boost Radiotherapyafter Conservative Breast Surgery in Early Breast Cancer. Advances in Breast Cancer Research, 5, 97-102.

10.Disipio T, Rye S, and Newman B: Incidence of unilateral arm lymphoedema after breast cancer: a systematic review and meta-analysis. Lancet Oncol 2013 ;14(6):500-15. 